\title{
CONF-871020--2
}

\section{PERFORMANCE CHARACTERISTICS OF NEUTRON PERSONNEL DOSEMETERS USED IN THE OAK RIDGE INTERCOMPARISON STUDIES:}

\section{R. E. Swaja}

Oak Ridge National Laboratory

P. O. Box X

Oak Ridge, Tennessee, USA
CONF-871020--2

DE87 014952

\section{1}

\begin{abstract}
To provide an opportunity for dosimetrists to test and calibrate their neutron personnel monitoring systems, the staff of the Dosimetry Applications Research Facility at the Oak Ridge National Laboratory (ORNL) has conducted personnel dosimetry intercomparison studies (PDIS) periodically since 1974. During these studies, neutron dosemeters are mailed to ORNL, exposed to low-level (less than $15 \mathrm{mSv}$ ) dose equivalents in a variety of mixed-radiation fields produced using the Health Physics Research Reactor (HPRR), and then returned to the participants for evaluation. Beginning with the Seventh PDIS in 1981, interest and participation in the Oak Ridge intercomparisons increased significantly and consistent and documented methods for determining reference neutron dose equivalents for the HPRR wera introduced. This paper presents a summary and analysis of about 3450 neutron dose equivalent measurements reported for PDIS 7 through 12 (1981-1986) with particular emphasis on low dose equivalent sensitivity, accuracy and precision, and performance relative to accreditation standards for tine basic types of personnel dosimetry systems.
\end{abstract}

*Research sponsored by the Physical and Technological Research Division, U.S. Department of Energy, under contract DE-AC05-840R21400 with Martin Marietta Energy Systems, Inc.

The submitted manuscript has been authored by a contractor of the U.S. Government under contract DE-ACO5-840R21400. Accordingly. the U.S. Government retains a nonexclusive, royalty-free license to publish or reproduce the published form of this contribution, or allow others to do so, for U. S. Government purposes.

\section{DISCLAIMER}


PERFORMANCE CHARACTERISTICS OF NEUTRON PERSONNEL DOSEMETERS

USED IN THE OAK RIDGE INTERCOMPARISON STUDIES

\author{
R.E. Swaja \\ Oak Ridge National Laboratory \\ P.O. Box X \\ Oak Ridge, Tennessee, USA 37831
}

\title{
INTRODUCTION
}

Interest in neutron personnel monitoring has increased significantly over the past several years due to the advent of dosimetry accreditation programs $(1)$ and proposed increases in neutron quality factors for radiation protection ${ }^{(2)}$. To provide an opportunity for dosimetrists to test and calibrate their personnel monitoring systens in a variety of mixed neutron and gamma radiation fields, the staff of the Dosimetry Applications Research (DOSAR) Facility at Oak Ridge National Laboratory (ORNL) has conducted personnel dosimetry intercomparison studies (PDIS) periodically since $1974^{(3-9)}$. During these studits, neutron dosemeters are mailed to ORNL, mounted on phantoms and exposed to low-level ( 0.40 to $15.21 \mathrm{mSv}$ ) dose equivalents in mixed-radiation fields produced using the Health Physics Research Reactor (HPRR) (10), and then returned to the participants for evaluation. Reported dose equivalents are compared to reference values provided by the DOSAR Staff and to results obtained by individual agencies who made measurements under identical exposure conditions. A total of 116 different organizations (78 from the United States and 38 from other countries) has participated in the twelve ORNL intercomparisons conducted to date. These organizations consist of nuclear utilities, industrial and government laboratories, military agencies, universities, vendor 
services, and hospitals.

Beginning with the Seventh PDIS in 1981, interest and participation in the Oak Ridge intercomparisons increased significantly and have remained high. This study also marked the introduction of consistent and documented techniques for determining reference neutron dose equivalents for the $\mathrm{HPRR}^{(11,12)}$. The following text presents a summary and analysis of about 3450 neutron dose equivalent measurements conducted during PDIS 7-12 using the HPRR as the primary source of radiation. Particular factors examined include threshold effects (10w dose equivalent sensitivity), measurement accuracy and precision, and performance relative to accreditation standards for the basic types of neutron dosemeters.

\section{INTERCOMPARISON DATA}

Most (about 908) of the reported neutron dose equivalents with the HPRR as the primary source of radiation have been measured for four different fields: the unshielded HPRR and the reactor shielded with $13-\mathrm{cm}$ of steel, $20-\mathrm{cm}$ of concrete, and $12-\mathrm{cm}$ of Lucite. Only results measured for these fields will be considered in the following analysis since they should provide the best indication of neutron dosemeter performance. Table 1 summarizes characteristics of these four radiarion fields including neutron mean energies, ratios of thermal-to-fast neutron fluences, and neutron-to-gamma dose equivalent ratios in air at the dosemeter exposure locations. The indicated fields range from a hard, almost equilibrium ${ }^{235} \mathrm{U}$ fission neutron spectrum with a relatively low thermal fluence and strong neutron component (unshielded HPRR) to a soft, hydrogen-moderated spectrum with a high thermal fluence and a 
strong gamma component (Lucite-shielded HPPR). Data giveri in Table I are for the most recent (PDIS 11 and 12) HPPR irradiation configuration (12). Radiation field characteristics(11) for PDIS 7-10 show qualitatively similar relationships between the spectra listed in the table.

Reference neutron dose equivalents for the HPRR are determinec using fission yields measured by sulfur pellet accivation anaiysis and dose-equivalent-per-fission conversion factors developed for various spectra $(11,12)$. In this analysis, reference neutron dose equivalents used for comparison to measured results are based on specifications given in ICRP-21(13). Approximately 428 of all agencies reporting results used this corvention for their neutron dose equivalents in PDIS 7-12. Two other conventions widely used by intercomparison participants are described in NCRP-38 ${ }^{(14)}$ and by Auxier and Snyder (element 57 convention) (15). These conventions were used by 268 and $16 \%$, respectively, of the responding participants. The remaining $16 \%$ of the participating organizations either used some other convention (68) or did not know what convention was associated with their reported results (108). For the four HPRR spectra considered in this evaluation, reference dose equivalents based on NCRP or element 57 specifications typically differ from corresponding ICRP-21 values by less than $108(8,9)$.

\section{NEUTRON DOSEMETER TYPES}

The 116 organizations who participated in PDIS 7-12 submitted a total of 5750 neutron monitoring badges which consisted of 4700 which were mounted on phantoms and exposed to various spectra and 1050 control 
dosemeters. Measured results were reporced for 3451 of the badges exposed to HPRR spectra. Although few of the badge designs submitted by different organizations were the same, the basic detection mechanisms can be classified into six categories: direct-interaction thermoluminescent (TID), TLD-albedo, ITA film, recoil track (mostly CP. 39 material), fission track (mostly thorium convertors), and combination albedo plus recoil track ${ }^{(16)}$. The TLD-based albedo and directinteraction systems, the most popular types used in PDIS 7-12, were used by 458 and $28 \%$, respectively, of the agencies who reported results. Recoil track systems were used by $11 \%$ of the reporting organizations. Film, combination, and fission track systems were used by 68,68 , and 48, respectively, of the responding agencies. From PDIS 7 th PDIS 12 , the percentage use of recoil track, combination, and fission track systems has remained relatively constant while TLD (albedo and directinteraction) use has increased slightly and film use has decreased slightly. In addition to these six basic dosemeter types, less than one percent of the neutron results for PDIS 7-12 were obtained using different methods such as other dosemeter types or estimating neutron dose equivalents from gamma results.

\section{DOSE EQUIVALENT SENSITIVITY}

To determine the low dose equivalent sensitivity of the various neutron dosemeter types, irradiations were conducted during PDIS 8,9, and $10^{(5-7)}$ at dose equivalent levels of about $0.5 \mathrm{mSv}(50 \mathrm{mrem})$. For each dosemeter type, Table 2 summarizes the total number of reported measurements, the number of reported measurements greater than zero or the minimum detectable value $(M)$, and the percent of measurements 
greater than zero for all irradiations. In general, the table shows that participancs who used TLD-based systems had farer probiems obtaining measurable indication of neutron exposure at about 0.5 msv than did those who used track-based systems. Albedo users had almost no problems obtaining measurable indjcation of neutron exposure at low dose equivalents in that oniy 48 of all reported results were zerc or below minimum detectable. Some of the participants who used combiration albedo plus track and direct-interaction TLD systems exhibited slightly greater difficulty obtaining measurable indication of neutron expostre with approximately 98 and $17 \%$, respectively, of the results being reported as zero or $M$. Although the small number of reportec measurements precludes a comprehensive evaluation of dosemeter response at low dose equivalents, about $25 \%$ of the fission track results were reported as zero. Approximately 298 of the measurements reported for film dosemeters were zero or $M$ for all spectra. Recoil track systems exhibited the most problems providing measurable results with about 478 of the data reported as zero. At this dose equivalent level, the percent: of measurements greater than zero or $M$ for the basic dosemeter types showed no obvious correlation with incident spectrum (7). The next lowest neutron dose equivalent considered in the ORNL intercomparisons was about $1.5 \mathrm{mSv}(150 \mathrm{mrem}){ }^{(9)}$ which is the lowest 1 imit specified for neutron accreditation testing ${ }^{(1)}$. None of the basic dosemeter types exhibiced any difficulty providing measurable indication of neutron exposure at dose equivalents of $1.5 \mathrm{ISv}$ or greater. 


\section{ACCURACY AND PRECISION}

The quantities of most concern to those involved in applied dosimetry or accreditation testing are measurement accuracy and precision. In this analysis, accuracy is indicated by the normalized dose equivalent which is the reported measured result divided by the reference neutron dose equivalent provided by the DOSAR staff. Measurement precision is indicated by one standard deviation about the mean of all measured results for a particular irradiation.

Table 3 shows measurement accuracy and the total number of measurements considered for each of the six basic dosemeter types. Data given in the table are based on results obtained in PDIS 7 through $12^{(4-9)}$ for reference neutron dose equivalents between 1.48 and 15.21 mSv. Accuracy values represent the average normalized results reported by all participants who used a particular dosemeter type for each spectrum. Thus, performance characteristics inferred from these results represent those expected from the "average" neutron dosimetry system. Standard deviations associated with the indicated data are about 258 of the means in each case.

For dosemeter types with more than 100 measurements, TLD-albedo dosemeters are overall the most accurate providing results within $28 \%$ of reference values for all spectra. The hardest spectra (unshielded and steel-shielded) are measured more accurately than the softest spectra (concrete- and Lucite-shielded) with the average normalized values increasing monotonically with ifcreasing spectrum softness; i.e., increasing thermal-to-fast fluence ratio. This performance is characteristic of albedo systems calibrated with hard sources (unmoderated $\mathrm{CF}, \mathrm{PuBe}$, or the unshielded HPRR) with no corrections 
applied to dosemeter response to account for differences between incident and calibration spectra $(4-0)$.

Direct-interaction TLD systems exhibit the same qualitative behavior as albedo systems in that hard spectra are measured more accurately than soft spectra with the average normalized values increasing monotonically with increasing spectrum softness. However, since direct-interaction TLD's are much more sensitive to thermal neutrons than albedo dosemeters, the amount of overestimation for the soft spectra is much greater for direct-interaction TLD systems. Some individual agencies who used direct-interaction systems calibrated to hard spectra overestimated Lucite-shielded dose equivalents by factors of three or more reiative to reference values.

On the averdge, film neutron dosemeters underestimated dose equivalents for all spectra and provided results between 628 and $70 \%$ of reference values. This performance has been observed in all ORNL intercomparisons and is a consequence of the threshold response characteristics of NTA film dosemeters, which are insensisive to neutrons with energies below about $500 \mathrm{keV}$, and the fact that most reporting organizations calibrated with sources much harder than any HPRR spectra; e.g., unmoderated $C f$ and PuBe. Recoil track (CR-39) systems, which also have a threshold energy sensitivity (insensitive to neutrons with energies below about $200 \mathrm{keV}$ ), generally provided underestimates of neutron dose equivalents for all spectra. Average measured results varied from 608 to $97 \%$ of reference values with the unshieldet HPRR spectrum being the most accurate. For each spectrum, average accuracies exhibited by recoil track systems are comparable to or significantly better than those exhibited by film dosemeters. 
Fission track systems (thorium convertor), which also have threshold response characteristics (insensitive to neutrons with energies below about $1 \mathrm{MeV}$ ), produced the most accurate average results with normalized values within 218 of reference dose equivalents for all spectra. However, the small number of reported results for this dosemeter type prevents any conclusive comparisons between fission track dosemeters and accuracies observed for other basic systems used in these studies.

Combination albedo plus recoil track dosemeters are designed to provide a wide range of neutron energy sensitivity by combining the strong sensitivity of albedo systems to intermediate energy neutrons with the strong sensitivity of recoil track dosemeters to fast neutrons. Table 3 shows that combination dosemeters provided average results from 708 to 1028 of reference values for all spectra. Qualitstively, variations in accuracy as a function of incident spectrum for combination systems were closer to those obserjed for recoil track dosemeters than for albedo systems in that average normalized results were very close to reference values for the unshielded HPRR spectrus and were lower than reference values for all moderated reactor specira.

With regard to measurement precision, single standard deviations about the mean of results reported by individual organizations averaged about 118 for all irradiations in which three or more badges were mounted side-by-side on a phantom. About 368 of all reporting organizations showed standard deviations of 58 o: less of the mean values while about 688 indicated standard deviations of 108 or less of the means. Albedo and cirect-interaction TLD systems exhibited the best precisions with average standard deviations of about 98 of the means and about 758 of all reporting organizations showing single standard 
deviations of 108 or less of the means. Fission track systems produced the poorest precisions with average standard deviations of about 183 of the means and approximately 258 of all reporting organizations showing single standard deviations of $10 \%$ or less. These results indicate that for well over half of the PDIS participants, measurement precision is not a problem relative to accuracy.

\section{CONCLUSIONS}

The following conclusions are based on observations presented in the preceding text:

1. For neutron monitoring, TLD-based systems (albedo and directinteraction) are the most popular among participants in the ORNL personnel dosimetry intercomparisons. Between PDIS 7 and 12 (1981 to 1986), the percentage use of recoil track, combination albedo-track, and fission track systems remained almost constant while TLD popularity has increased slightly and film use has decreased slightly.

2. Most (428) participating organizations reported neutron dose equivalents in the ICRP-21 convention. About 268 and 168 used the NCRP-38 and element 57 conventions. About 108 of all responding participancs did not know what convention was associated with their results.

3. Participants who used TLD-based systems had fewer problems obtaining measurable indication of neutron exposure at dose equivalent levels of about $0.5 \mathrm{mSv}$ than did those who used track-based systems. None of the basic dosemeter types exhibited any sensitivity problems at neutron dose equivalents greater than about $1.5 \mathrm{mSv}$. 
4. Overall, TLD-albedo dosemeters were the most accurate with average results within 288 of reference values for all HPRR spectra. Best resuits were obtained for the hardest neutron energy spectrum with dose equivalents for moderated reactor spectra being overestimated relative to reference values. Direct-interaction TLD systems showed the same qualitative performance as albedo dosemeters but exibited much greater overestimates for moderated spectra.

5. Track-based systems (film and recoil track) provided average dose equivalents which were lower than reference values for all spectra. Fission track dosemeters, which had the fewest reported measurements of all the basic dosemeter types, exhibited good average accuracy but the poorest precision. Performance :baracteristics of combination albedotrack dosemeters were qualitatively much closer to those observed for recoil track systems than for aldebo systems.

6. Neutron measurement precision as reflected by one standard deviation about the mean of results were within 10 \% of the means for $68 \%$ of the reporting organizations. These results indicate that for over half of the PDIS participants, measurement precision is not a problem compared to accuracy.

\section{RECOMMENDATIONS}

The large number of participants in the ORNL intercomparisons conducted since 1981 indicates that dosimetrists are concerned with testing and evaluating performance characteristics of their personnel monitoring systems in radiation fields beyond the scope of those considered in accreditation testing. To facilitate these efforts, the DOSAR staff plans to continue the annual intercomparison program and to 
increase the scope of the radiation fields and exposure conditions. In addition, a comprehensive radiation calibration facility is now being constructed at ORNL to greatly expand DOSAR irradiation capabilities. 


\section{REFERENCES}

1. American National Standards Institute, "Criteria for Testing Personnel Dosimetry Performance", ANSI N13.11-1983, January 1983.

2. International Commission on Radiological Protection, "Statement from the 1985 Paris Meeting of the International Commission on Radiological Protection", Radiat. Prot. Dosim. 11(2) 134-135 (1985).

3. Sims, C.S. and Swaja, R.E. "Personnel Dosimetry Intercomparison Studies at the Health Physics Research Reactor: A Summary (19741980)", Health Phys. 42(1) 3-18 (1982).

4. Swaja, R.E., Sims, C.S., and Greene, R.T. "Seventh PersonneI Dosimetry Intercomparison Study", Oak Ridge National Laboratory Report ORNL/TM-8080, December 1981.

5. Swaja, R.E., Sims, C.S., Greene, R.T., Schraube, H., and Burger, G. "1982 US-CEC Neutron Personnel Dosimetry Intercomparison Study", Oak Ridge National Laboratory Report ORNL/TM-8697, November 1982.

6. Swaja, R.E., Sims, C.S., and Greene, R.T. "1983 OKNL Intercomparison of Neutron and Gamma Personnel Dosimeters", Dak Ridge National Laboratory Report ORNL-6126, January 1985.

7. Swaja, R.E., Chou, T.L., Sims, C.S., and Greene, R.T. "Tenth ORNL Pesonnel Dosimetry Intercomparison Study", Oak Ridge National Laboratory Report ORNL-6143, March 1985.

8. Swaja, R.E., Oyan, R., and Sims, C.S. "Eleventh ORNL Personnel Dosimetry Intercomparison Study: May 22-23, 1985", Oak Ridge National Laboratory Report ORNL-6296, July 1986.

9. Swaja, R.E., Weng, P.S., Sims, C.S., and Yeh, S.H. "Summary and Analysis of the 1986 ORNL Personnel Dosimetry Intercomparison Study", Oak Ridge National Laboratory Report ORNL-6378, April 19.87.

10. Auxier, J.A. "The Health Physics Research Reactor", Health Phys. 11 (1) $89-93$ (1965).

11. Sims, C.S. and Killough, G.G. "Reference Dosimetry for various Health Physics Research Reactor Spectra", Oak Ridge National Laboratory Report ORNL/TM-7748, July 1981.

12. Sims, C.S. and Ragan, G.E. "Health Physics Research Reactor Reference Dosimetry", Oak Ridge National Laboratory Report ORNL6240 , June 1987.

13. International Commission on Radiological Protection, "Data for Protection Against Ionizing Radiation from External Sources: Supplement to ICRP Publication 15", ICRP Publication 21, 1973. 
14. National Council on Radiation Protection and Measurements, "Protection Against Neutron Radiation", NCRP Report 38, 1971.

15. Auxier, J.A., Snyder, W.S., and Jones, T.D. "Neutron Interactions and Penetration in Tissue". Radiation Dosimetry $1275-280,1968$.

16. Griffith, R.V., Hankins, D.E., Gammage, R.B., Tommasino, I., and Wheeler, R.V. "Recent Developments in Personnel Neutron Dosimeters: A Review", Health Phys. 36(2) 235-260 (1970). 


\section{LIST OF TABLES}

1. HPRR radiation field characteristics at the dosemeter exposure locations.

2. Dose equivalent sensitivity for various neutron dosemeter types.

3. Measurement accuracy for various neutron dosemeter types in $H P R R$ radiation fields. 
Table 1. HPRR radiation field characteristics at the dosemeter exposure locations

\begin{tabular}{llll}
\hline Shield & $\begin{array}{c}\text { Average neutron } \\
\text { energy, MeV }\end{array}$ & $\begin{array}{c}\text { Ratio of thermal- } \\
\text { to fast fluence }\end{array}$ & $\begin{array}{c}\text { Neutron-to-gamma } \\
\text { dose equivalent } \\
\text { ratio }\end{array}$ \\
\hline Unshielded & 1.306 & 0.020 & 62.6 \\
$13-\mathrm{cm}$ steel & 0.780 & 0.030 & 86.6 \\
$20-\mathrm{cm}$ concrete & 0.885 & 0.257 & 22.0 \\
$12-\mathrm{cm}$ Lucite & 0.951 & 0.357 & 11.8 \\
\hline
\end{tabular}

${ }^{a}$ Data at three meters from the HPRR with the reactor operated over the storage pit at $1.4 \mathrm{~m}$ above the floor.

$b_{\text {Thermal }}(E \leq 0.5 \mathrm{eV}$ ) fluence divided by fast ( $\geq 1 \mathrm{MeV}$ ) fluence. 
Table 2. Dose equivalent sensitivity for various neutron dosemerer types

\begin{tabular}{|c|c|c|c|}
\hline Dosemeter type & $\begin{array}{l}\text { Total reported } \\
\text { measurements }\end{array}$ & $\begin{array}{c}\text { Number of results } \\
>0 \text { or } \mathrm{M}^{\mathrm{b}}\end{array}$ & $\begin{array}{l}\text { Percent of results } \\
>0 \text { or }\end{array}$ \\
\hline
\end{tabular}

\begin{tabular}{lccc}
\hline TLD-albedo & 464 & 445 & 96 \\
$\begin{array}{l}\text { Combination albedo } \\
\text { plus track }\end{array}$ & 64 & 58 & 91 \\
TLD-direct & 96 & 80 & 83 \\
Fission track & 8 & 6 & 75 \\
NTA film & 112 & 80 & 71 \\
Recoil track & 81 & 43 & 53 \\
\hline
\end{tabular}

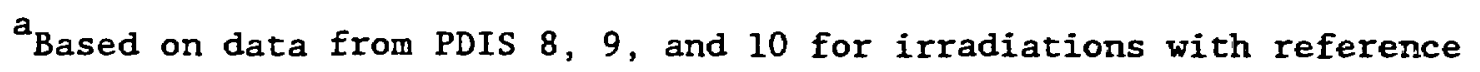
neutron dose equivalents of about $0.5 \mathrm{mSv}$.

$b_{M}=$ Minimum detectable value. 
Table 3. Measurement accuracy for various neutron dosemeter types in HPRR radiation fields

\begin{tabular}{lcccccc}
\hline $\begin{array}{l}\text { HPRR } \\
\text { shield }\end{array}$ & \multicolumn{5}{c}{ Average normalized neutron dose equivalents } \\
\cline { 2 - 6 } & TLD-albedo & TLD-direct & Film & $\begin{array}{c}\text { Recoil } \\
\text { track }\end{array}$ & $\begin{array}{c}\text { Fission } \\
\text { track }\end{array}$ & $\begin{array}{c}\text { Combination } \\
\text { albedottrack }\end{array}$ \\
\hline None & 1.09 & 0.94 & 0.66 & 0.97 & 1.20 & 1.02 \\
13 -cm steel & 1.12 & 0.95 & 0.62 & 0.68 & 1.21 & 0.70 \\
20 -cm concrete & 1.21 & 1.36 & 0.63 & 0.60 & 1.03 & 0.75 \\
12 -cm Lucite & 1.28 & 1.74 & 0.70 & 0.84 & 0.95 & 0.96 \\
\hline $\begin{array}{l}\text { Number of } \\
\text { measurements }\end{array}$ & 1023 & 459 & 121 & 192 & 48 & 110 \\
\hline
\end{tabular}

a Based on data from PDIS 7-12 for irradiations with reference neutron dose equivalents greater than $1.5 \mathrm{mSv}$.

${ }^{b}$ Average of measured divided by reference values for each spectrum. Associated standard deviations are about 258 of the means in each case. 